\title{
O sistema de gestão ambiental como impulsor da educação ambiental: um estudo de caso em uma empresa do polo industrial de Manaus (PIM) a partir da percepção de seus colaboradores
}

\author{
Ádria de Azevedo Araújo', Tereza Maria Pereira Bezerra', Haydy Soraya Urday Del Carpio', Sarah Nair \\ Nascimento dos Santos', Patrícia Auxiliadora Ribeiro de França², Maria da Glória Vitório Guimarães ${ }^{3}$ \\ I Graduandas em Administração, Universidade Federal do Amazonas \\ 2 Mestranda em Engenharia de Produção, Universidade Federal do Amazonas \\ ${ }_{3}^{3}$ Mestre em Engenharia de Produção, Universidade Federal do Amazonas
}

\begin{abstract}
Resumo
Este trabalho teve como ponto de partida encontrar resposta à seguinte problematização: em que medida o Sistema de Gestão Ambiental (SGA) adotado por uma empresa do Polo Industrial de Manaus (PIM) tem contribuído para a Educação Ambiental (EA) de seus colaboradores? Em decorrência de tal pergunta, o trabalho teve como objetivo geral verificar, a partir da percepção de colaboradores, se a empresa pesquisada, localizada no Polo Industrial de Manaus e que possui Sistema de Gestão Ambiental, contribui para a educação ambiental dos seus funcionários. Especificamente pretende-se identificar: - se e como ocorre o processo de educação ambiental em empresa com certificação ISO 14.001; - se a empresa pesquisada apoia e incentiva a criação de projetos pelos seus colaboradores que visam à preservação ambiental; - se, decorrentes dos processos de gestão ambiental e educação ambiental, ocorrem reflexões e mudanças de atitudes referentes a questões ambientais no contexto profissional e pessoal dos trabalhadores da empresa estudada; - e ainda, verificar o grau de interesse dos funcionários com relação às questões ambientais. Para tanto, foi realizado um estudo de caso, com pesquisa empírica do tipo descritiva, sobretudo na forma de trabalho de campo. Os principais resultados se mostraram concernentes com as abordagens de importantes autores da literatura sobre o assunto. Pode-se concluir que a EA, como uma ferramenta advinda do SGA, contribui para o processo de conscientização dos colaboradores, onde estes adquirem condições de assumir o papel de agentes de mudança em qualquer contexto e situação, influenciando, inclusive, em suas práticas pessoais e profissionais, bem como, adquirem a capacidade de disseminar informações sobre a temática ambiental para aqueles que o circundam, como seus familiares, amigos e colegas de trabalho; além de possuírem um elevado grau de interesse em relação às questões ambientais, também percebem tais práticas com extremo valor para enfrentar delicados problemas ambientais.
\end{abstract}

Palavras-chaves: Sistema de gestão ambiental; Educação ambiental; Percepção dos colaboradores.

\begin{abstract}
This work had as a starting point to find answers to the following questioning: to what extent the Environmental Management System (EMS) adopted by a company of the Industrial Pole of Manaus (PIM) has contributed to Environmental Education (EE) of its employees? As a result of such inquiry, the work had as objective to verify general, the perception of employees, the company researched, located in the Industrial Pole of Manaus and has Environmental Management System, contributes to the environmental education of its employees. Specifically aims to identify: - if and how the process of environmental education company with ISO 14001 certification occurs; - If the company researched supports and encourages the creation of projects for their employees aimed at environmental preservation; - Whether arising from processes of environmental management and environmental education, reflections and changes in attitudes toward environmental issues occur in the context of professional and personal company workers studied; - And yet, check the degree of interest of employees with regard to environmental issues. To this end, a case study with empirical descriptive research was conducted mainly in the form of fieldwork. The main results were concerning with the approaches of important authors in the literature on the subject. It can be concluded that EA, arising as a tool of the EMS, contributes to the process of awareness of employees, where they acquire the means to assume the role of change agents in any context and situation, influencing, even in their personal practices and professionals, as well as acquire the ability to disseminate information on environmental issues to those around, as their family, friends and coworkers; besides having a high degree of interest in environmental issues, also perceive such practices with extreme courage to face delicate environmental problems. reviewing the literature it was found that the ME, despite bringing positive aspects, will not solve the problems of Brazilian society . There is therefore the need to think of a new environmental policy and allied to the government concerned to participate in an environmentally smartening population, in all spheres, in a massive way and only way we can entertain the possibility of achieving concrete actions, among these, the effectiveness of ME in Brazil and different scenarios that may benefit the environment.
\end{abstract}

Keywords: Environmental management system, Environmental education, Perception of employees. 


\section{INTRODUÇÃO}

Nos últimos anos, tanto na dimensão governamental quanto na dimensão privada, diversas discussões e práticas sociais em relação ao meio ambiente têm sido realizadas, com a finalidade de amenizar a crise ambiental. Nesse contexto, cada vez mais as empresas buscam adotar algum tipo de política ambiental em seu planejamento, e entre elas, Programas de Educação Ambiental (PEA) ganham um papel relevante na construção de valores, caminhando além dos objetivos previstos para os treinamentos indicados pela International Organization for Standardization (ISO) 14.000.

Segundo Rodrigues et al. (2008), a ISO Série 14.000 é um grupo de normas que fornece ferramentas e estabelece um padrão de Sistema de Gestão Ambiental. Estas normas abrangem, seis áreas bem definidas: Sistemas de Gestão Ambiental, Auditorias Ambientais, Avaliação de Desempenho Ambiental, Rotulagem Ambiental, Aspectos Ambientais nas Normas de Produtos e Análise do Ciclo de Vido do Produto.

Ressaltam ainda os estudiosos acima que diante das diversas normas que compreendem a ISO Série 14.000, as empresas interessadas na obtenção de certificado devem adotar a norma ISO 14.001, pois, apenas esta, é formulada para fins de certificação junto a entidades independentes.

Segundo Alcântara e Silva (2012), o Sistema de Gestão Ambiental (SGA) possui vários objetivos a serem concretizados, pois cria técnicas, planeja, organiza e administra atividades econômicas e sociais visando à racionalização do manuseio dos recursos naturais, tem caráter multidisciplinar e, além do mais, necessita de decisões em curto prazo para garantir a preservação e a conservação da biodiversidade.

Os Sistemas de Gestão Ambiental (SGA) são definidos, segundo a NBR ISO 14.001, como a parte do sistema de gestão que compreende a estrutura organizacional, as responsabilidades, as práticas, os procedimentos, os processos e os recursos para aplicar, elaborar, revisar e manter a politica ambiental da empresa. Desta forma, têm-se várias certificações para que empresas apliquem o pensamento ambiental e sustentável, por meio de técnicas e soluções (ALCÂNTARA e SILVA, 2012).

É notória que as práticas de gestão ambiental são pautadas e interligadas a diversas normas em prol da minimização de impactos negativos gerados ao meio ambiente. Molin (2009) ilustra que a gestão ambiental é o principal instrumento para se obter um desenvolvimento industrial sustentável. O processo de gestão ambiental nas empresas está profundamente vinculado a normas que são elaboradas pelas instituições públicas (prefeituras, governos estaduais e federais) sobre o meio ambiente. Estas normas fixam os limites aceitáveis de emissão de substâncias poluentes, definem em que condições serão despojados os resíduos, proíbem a utilização de substâncias tóxicas, definem a quantidade de água que pode ser utilizada, volume de esgoto que pode ser lançado, etc.

Sell (2006, apud MOLIN, 2009) destaca que a gestão ambiental não é tarefa apenas de alguns funcionários da empresa, pertencendo à função gerencial e abrange todos os setores, que estão envolvidos de alguma forma com o planejamento, execução, revisão e desenvolvimento da politica ambiental da organização, necessitando que haja compatibilização com os anseios da administração e dos setores operacionais.

Logo, percebe-se que as empresas que adotam o SGA, como um diferencial em face ao mercado competitivo e a degradação inconsciente do meio ambiente, destacam-se, pois garantem qualidade dos produtos, serviços e processos, economia ou a minimização no consumo de matérias-primas e energia, aumento da demanda por seus produtos, pois os atuais consumidores exigem uma postura racional e sustentável das empresas.

Ademais, fica evidente que as organizações que possuírem um comprometimento ambiental aumentam as suas possibilidades de êxito tanto em relação à conquista e permanência de seus consumidores quanto à diminuição das consequências negativas voltadas ao meio ambiente.

De acordo com Macedo (2010), uma das principais razões para a implantação da ISO 14.001 pelas indústrias é o aumento de sua competitividade junto ao mercado internacional. Empresas com esta certificação têm mais chances de conquistar mercados onde questões relativas ao meio ambiente são consideradas fundamentais para tomado de decisão comercial. Além disto, a certificação ISO 14.001 evidencia a todas as partes interessadas que a organização está comprometida com a melhoria contínua de seu desempenho ambiental.

Vale ressaltar que no requisito competência, treinamento e conscientização a NBR ISO 14.001 (2004, p. 6) especifica que: 
A organização deve assegurar que qualquer pessoa que, para ela ou em seu nome, realize tarefas que tenham o potencial de causar impacto (s) ambiental (is) significativo (s) identificados pela organização, seja competente com base em formação apropriada, treinamento ou experiência, devendo reter os registros associados. A organização deve identificar as necessidades de treinamento associadas com seus aspectos ambientais e seu sistema da gestão ambiental. Ela deve prover treinamento ou tomar alguma ação para atender a essas necessidades, devendo manter os registros associados.

Em decorrência disto, é que as organizações que implantam um SGA, devem treinar e capacitar seus funcionários, incluindo, desta forma, terceirizados, estagiários e fornecedores, a fim de se tentar controlar os impactos gerados ao meio ambiente.

É neste sentido, que Vilela Júnior e Demajorovic (2006) salientam a necessidade da ampliação dos horizontes da empresa e de seus funcionários, demandando que uma nova cultura seja construída. Muito além dos treinamentos para os empregados, as empresas precisam pensar que estão lidando com pessoas, com individualidades, com histórias de vida, com crenças, valores e culturas, ou seja, com hábitos que determinam comportamentos, consolidando-se, então, um cenário muito mais complexo que implica ações tanto no ambiente interno da empresa quanto no externo.

Para Valle (2006), a inserção dessas ações na cultura da organização exige um sistema de comunicação eficiente entre seus vários níveis hierárquicos, por meio do estabelecimento de um Programa de Educação Ambiental (PEA) que mobilize todos os seus integrantes.

Neste sentido, a Educação Ambiental (EA) ganha evidência como uma ferramenta indispensável, nos dias atuais, devido à notória degradação irracional dos recursos naturais disponíveis e pela exigência dos empresários para maiores comprometimentos e responsabilidades ambientais, com o intuito de estimular ações que além de visarem ao lucro contemplem e estimulem a educação e as práticas ambientais.

Sob a ótica de Rocha (2000) apud Silva et al. (2005, p.3) o conceito de educação ambiental refere-se a:

Um processo de tomada de consciência política, institucional e comunitária da realidade ambiental, do homem e da sociedade, para analisar, em conjunto com seu público externo, por meio de mecanismos formais e não formais, as melhores alternativas de proteção da natureza e do desenvolvimento socioeconômico do homem e da sociedade.

Para Torres e Balassiano (2010) educar, nesse sentido, implica oferecer métodos eficazes e pertinentes ao desenvolvimento de práticas sociais centradas, essencialmente, no conceito de natureza, e não na lógica capitalista. Deve, ainda, a educação ambiental promover a reflexão sobre as dimensões do progresso humano, sobre o impacto que este causa ao meio ambiente em detrimento do desenvolvimento tecnológico, em especial.

A educação ambiental deve está voltada tanto para os empresários, funcionários, colaboradores e fornecedores quanto para os consumidores, em geral, a fim de tentar modificar certos hábitos nocivos para o desenvolvimento sustentável da sociedade. Esta nova concepção deve ser fomentada por meio de programas ambientais que envolvam todos os níveis hierárquicos da organização e que mobilizem os seus integrantes a absorverem e a disseminarem estas novas práticas que conduzem a um novo fator de progresso.

Outrossim, a educação ambiental deve ser visualizada como uma mudança de atitudes e ser colocada como um ato político voltado para a transformação social, não se esquecendo da necessidade da sustentabilidade ecológica, social e econômica (ALCANTARA e SILVA 2012).

Segundo Penatti e Silva (2008), a educação ambiental, quando praticada no ambiente organizacional, conduz os funcionários a uma mudança de comportamento e atitudes em relação ao meio ambiente interno e externo de sua empresa, despertando o interesse em cada colaborador na ação e busca de soluções concretas para os problemas ambientais que ocorrem principalmente no seu dia a dia.

Para Vilela Júnior e Demajorovic (2006), com o processo de educação ambiental os funcionários adquirem condições de assumir o papel de agentes de mudança em qualquer contexto e situação. Neste sentido, a empresa deve promover a curiosidade e a construção de conhecimento estimulando os empregados a contribuírem, por meio de sugestões, com o melhor desempenho pessoal e da corporação. 
De acordo com estes autores, se as empresas se limitam a desenvolver programas de educação ambiental voltados a dar atendimento somente às auditorias, tanto de certificação como de manutenção, na melhor das hipóteses, o que se obtém é a gestão ambiental por espasmos, um grande desempenho na arrumação da casa às vésperas das auditorias é um grande alívio e descaso ao final das mesmas.

Infelizmente algumas empresas ainda veem a educação ambiental apenas como um mecanismo para a redução na utilização de recursos naturais, no sentido de redução de custos e não demonstrando preocupação com sua extinção, bem como combate ao desperdício, e que, além disso, ela deva ser aplicada apenas aos funcionários que possam promover um impacto ambiental significativo. Outro fator preocupante é o fato da educação ambiental estar sendo desenvolvida única e exclusivamente em função de um requisito da Norma ISO 14.001, e se a mesma não for atendida integralmente, na próxima auditoria a certificação pode ser perdida devido a tal não-conformidade (MEDEIROS, 2004).

Conforme Motta (2010), um programa de educação ambiental não pode ficar restrito a um programa de treinamento, como requisito de um SGA, por exemplo, visando à sensibilização e motivação dos funcionários, e sim atuar de forma ativa no próprio posto de trabalho dos operadores. Para o mesmo autor, a educação ambiental é um grande agente catalisador do processo de interação dentro da empresa, motivo pelo qual a EA é uma ferramenta essencial para o SGA.

Assim, o Sistema de Gestão Ambiental (SGA) e os avanços conquistados na Educação Ambiental (EA) são focos deste trabalho, cuja realização tem como ponto de partida encontrar resposta à problematização: em que medida o SGA adotado por uma empresa do Polo Industrial de Manaus (PIM) tem contribuído para a EA de seus colaboradores?

Acredita-se que a educação ambiental é um agente catalisador do processo de interação dentro de uma empresa e não pode ficar restrita ao treinamento, visando à sensibilização e motivação dos funcionários, embora contribua para a construção de um sistema de gestão ambiental que estará permeando desde o trato com o chão da empresa até o modo de tratamento com os funcionários de modo eficaz e não simplesmente pelo desejo de cumprir um requisito que vise à certificação.

Isto posto, este trabalho tem como objetivo geral verificar, a partir da percepção de colaboradores, se a empresa pesquisada, localizada no Polo Industrial de Manaus (PIM) e que possui Sistema de Gestão Ambiental (SGA), contribui para a educação ambiental dos seus funcionários ou em suas práticas pessoais e profissionais.

Especificamente pretende-se identificar: - se e como ocorre o processo de educação ambiental em empresa com certificação ISO 14.001; - se a empresa pesquisada apoia e incentiva a criação de projetos pelos seus colaboradores que visam à preservação ambiental; - se, decorrentes dos processos de gestão ambiental e educação ambiental, ocorrem reflexões e mudanças de atitudes referentes a questões ambientais no contexto profissional e pessoal dos trabalhadores da empresa estudada; - e ainda, verificar o grau de interesse dos funcionários com relação às questões ambientais.

Pelos argumentos anteriores é possível expor que a justificativa pela escolha do tema dá-se por ser de suma importância se procurar, por meio da educação ambiental, estimular reflexões na classe empresarial, pesquisadores, técnicos e estudantes para assim promover uma contribuição prática de melhoria continua. Isto desenvolvendo, simultaneamente, uma consciência coletiva e ecológica para a preservação do meio ambiente.

\section{METODOLOGIA}

A pesquisa, enfatiza Prestes (2007), designa um conjunto de atividades que têm como finalidade descobrir novos conhecimentos. Daí a necessidade de assegurar sua dimensão de cientificidade, descrever, de modo o mais preciso possível, o que ela é e como se deu sua realização. Neste sentido, ainda com base em Prestes (2007), considerando o objetivo deste trabalho, define-se como pesquisa empírica, posto que se volta para esclarecer a problemática observada, objetivando codificar o lado mensurável da realidade.

No que se refere à forma de estudo do objeto da pesquisa, ela é do tipo descritiva. Isto porque o fenômeno sob estudo foi observado, registrado, analisado e interpretado sem qualquer interferência das pesquisadoras. Quanto ao objeto de estudo a pesquisa revela-se, sobretudo, de campo, haja vista o uso que se faz de questionários autoadministrados, por meio dos quais ocorreu a coleta dos dados, investigando os participantes em seus próprios meios. Estas duas últimas classificações, vale dizer, 
também tendo como referência o que esclarece Prestes (2007).

Tendo como locus o Polo Industrial de Manaus - PIM, as pesquisadoras desenvolveram a coleta de dados, no mês de maio de 2014, junto a colaboradores de uma industrial multinacional, com filial em Manaus, que atua no ramo de material de escritório. O instrumento adotado foi o questionário, contendo 8 (oito) questões de múltipla escolha que são perguntas fechadas, mas que apresentam uma série de possíveis respostas, abrangendo várias facetas do mesmo assunto. O questionário foi aplicado a 60 (sessenta) colaboradores da empresa, gerando dados que, a partir da estatística descritiva, por meio do programa Statistical Package for the Social Sciences (SPSS) - Pacote Estatístico para as Ciências Sociais, foram interpretados ou representados como se apresenta e se discute posteriormente.

\section{RESULTADOS E DISCUSSÕES}

Os colaboradores, primeiramente, foram perguntados até que ponto consideram que sua empresa promove palestras ou seminários que incentivam a conscientização ambiental daqueles. Os dados revelaram que, conforme a figura 1 , somente $5 \%$ dos entrevistados disseram que nunca sua empresa promove essas práticas, $7 \%$ indicaram raramente, $13 \%$ disseram somente às vezes, $30 \%$ apontaram quase sempre, seguido de $45 \%$ que consideraram que sua empresa sempre promove internamente programas voltados para a conscientização ambiental dos mesmos, o que é uma decorrência das ações implementadas por meio da NBR ISO 14.001 onde especifica que a organização deve identificar as necessidades de treinamento associadas com seus aspectos ambientais e seu sistema da gestão ambiental. Assim, deve prover treinamento ou tomar alguma ação para atender a essas necessidades, devendo manter os registros associados.

A pesquisa também revelou, como se vê na figura 2, que 17\% dos colaboradores apontaram que somente às vezes sua empresa apoia e incentiva projetos desenvolvidos pelos funcionários, $25 \%$ disseram que quase sempre isto acontece, seguido de $47 \%$ que afirmaram que sua empresa sempre apoia e incentiva projetos desenvolvidos pelos colaboradores, o que enfatiza as considerações de Torres e Balassiano (2010) acerca da educação ambiental, que quando implementada na organização, deve promover a reflexão dos colaboradores sobre as dimensões do progresso humano, sobre o impacto que este causa ao meio ambiente em detrimento do desenvolvimento tecnológico, em especial.

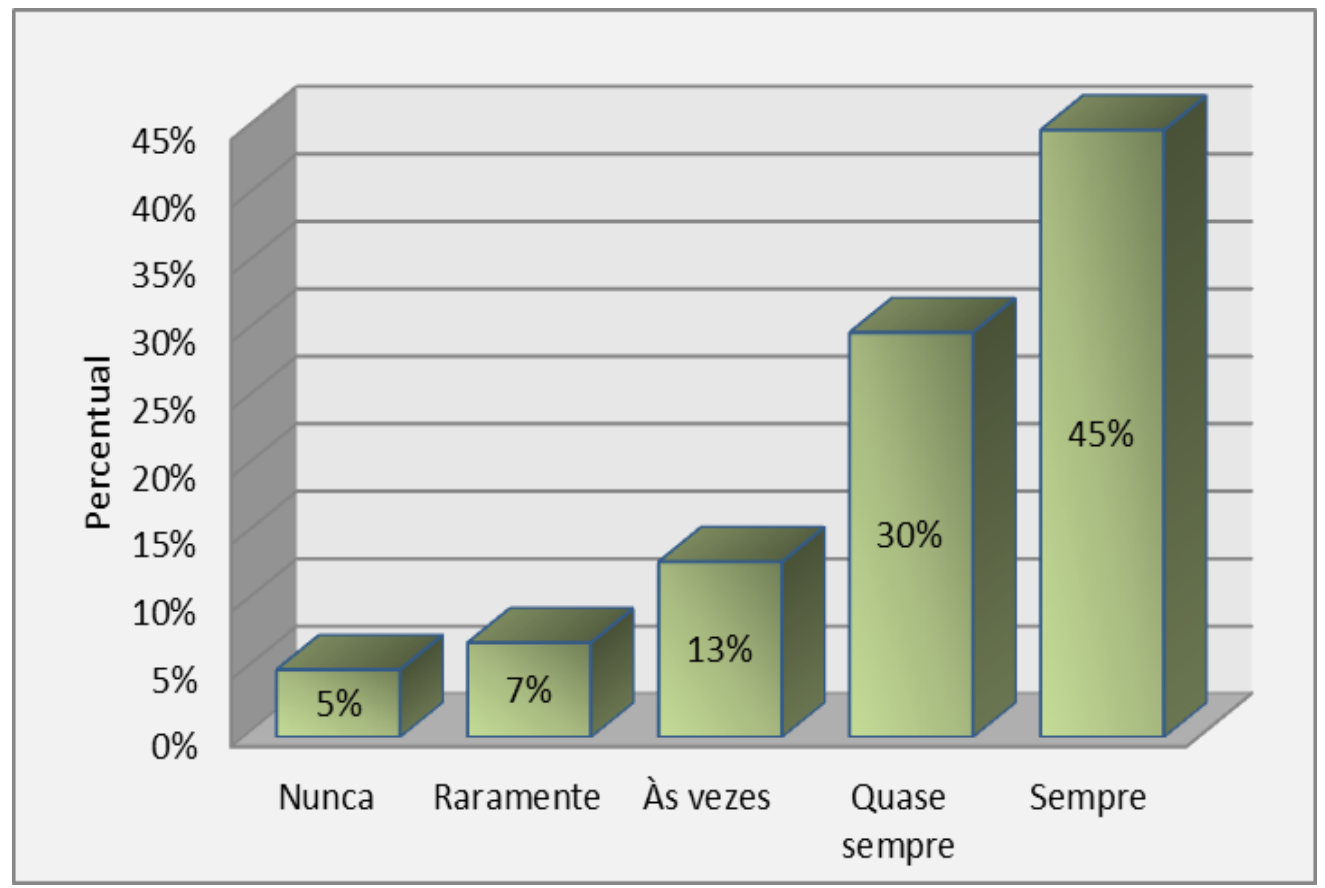

Figura 1: Promove palestras ou seminários

Fonte: Elaborada pelas autoras 


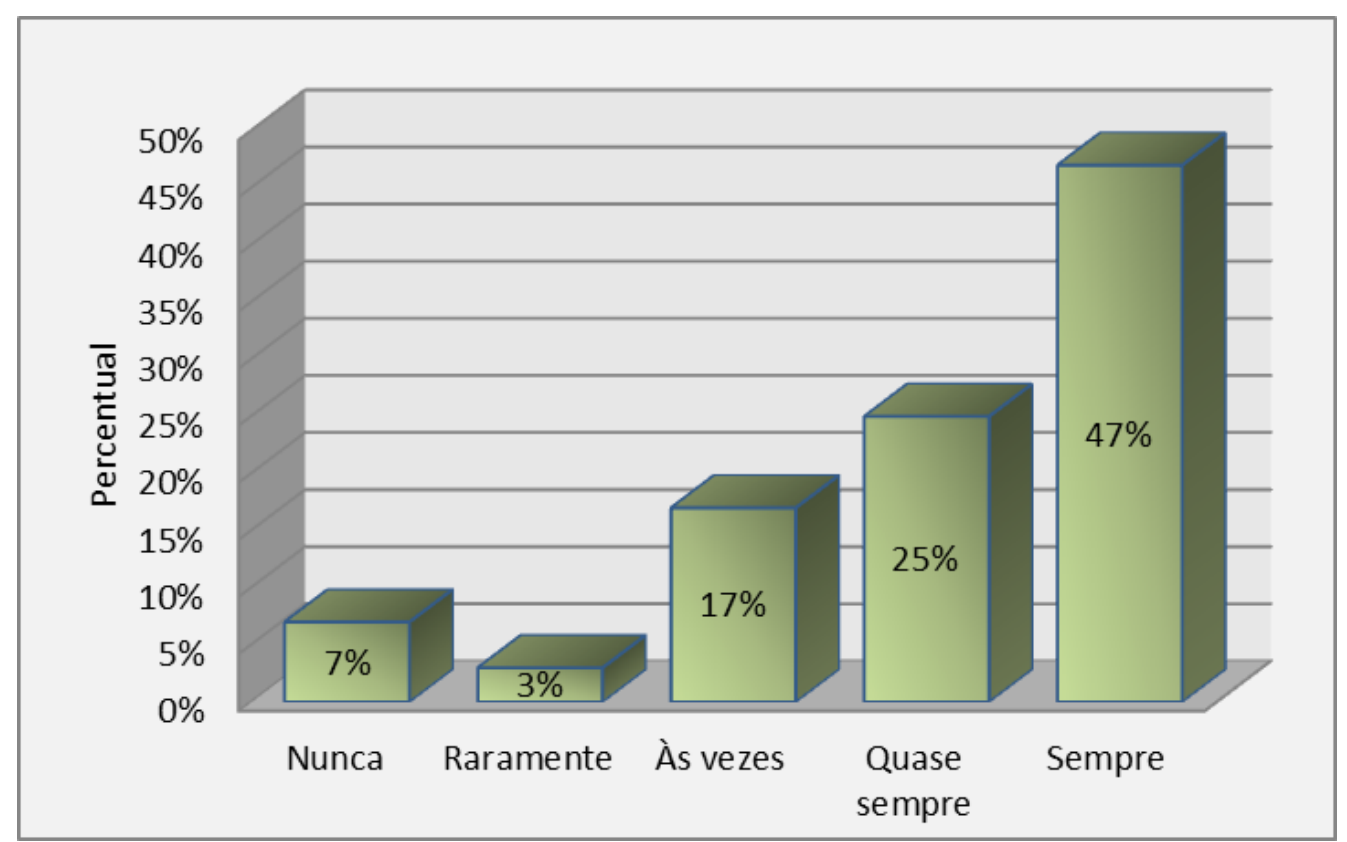

Figura 2: Apoia e incentiva projetos desenvolvidos pelos funcionários Fonte: Elaborada pelas autoras

Quando os participantes foram perguntados até que ponto as informações sobre meio ambiente os motivaram a mudar de atitude dentro da empresa, $30 \%$ disseram quase sempre, seguido de $60 \%$ que concluíram que sempre essa mudança acontece, como aponta a figura 3. Também foram perguntados em que medida ocorre mudança de atitudes em casa por causa de alguma informação sobre meio ambiente promovida por sua empresa, $35 \%$ disseram que quase sempre isso acontece, seguido de $47 \%$ que constataram que sempre mudam de atitude em casa devido às informações recebidas pela empresa, de acordo com a figura 4. Tais dados revelaram o que já evidenciavam Alcântara e Silva (2012) acerca da educação ambiental que deve ser visualizada como uma mudança de atitudes, tanto em casa como no ambiente empresarial, e ser colocada como um ato político voltado para a transformação social.

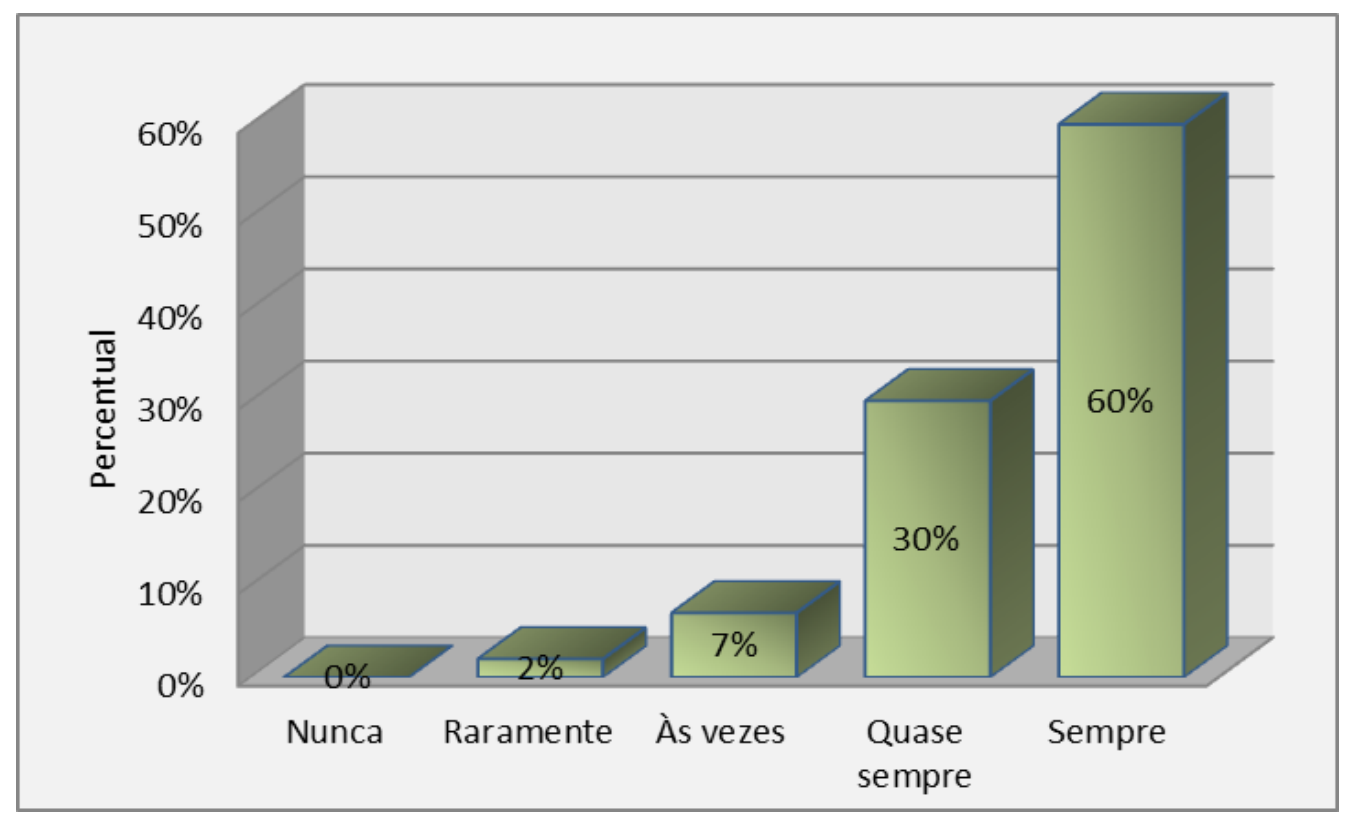

Figura 3: Mudanças de atitudes na empresa

Fonte: Elaborada pelas autoras 


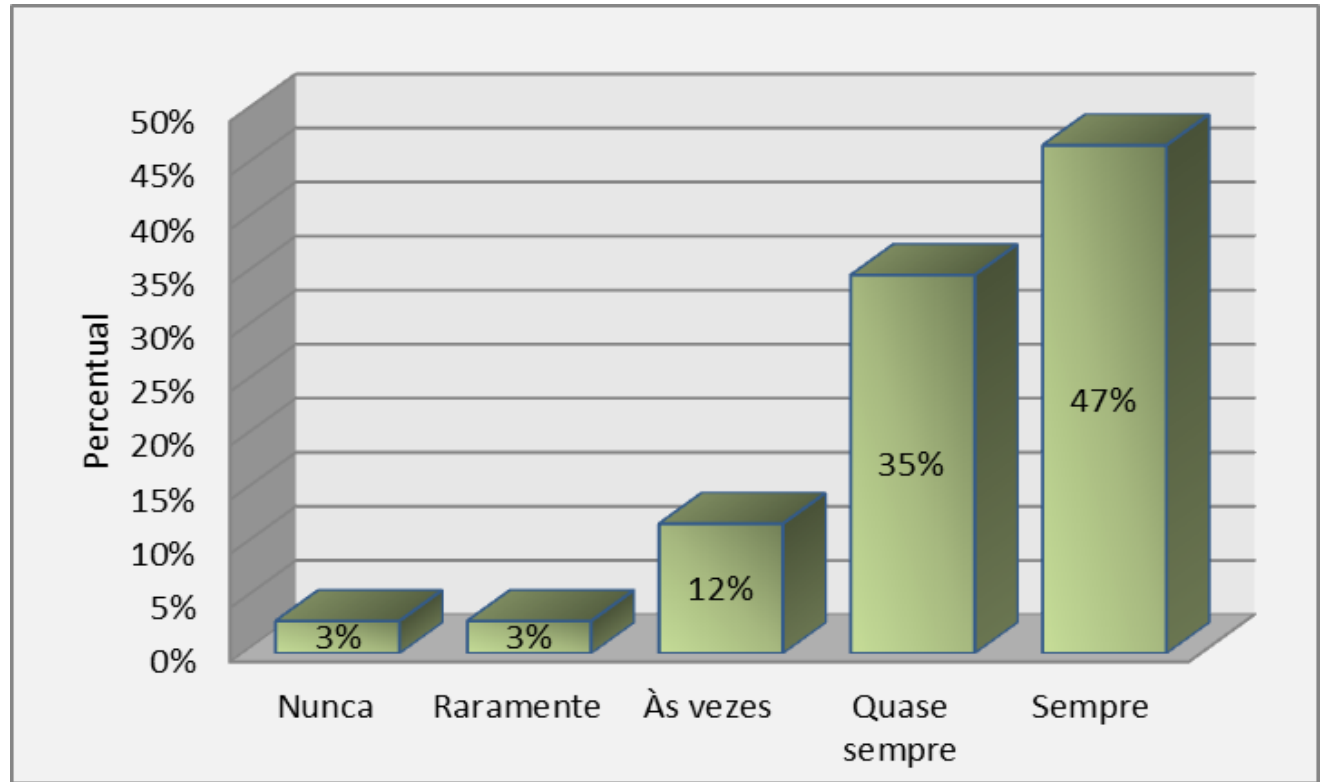

Figura 4: Mudanças de atitudes em casa Fonte: Elaborada pelas autoras

As questões 5 e 6 versam sobre a retransmissão das informações obtidas dos processos de educação ambiental da empresa tanto para os amigos, familiares ou para colegas de trabalho. A pesquisa revelou que $37 \%$ dos colaboradores disseram que quase sempre retransmitem as informações recebidas na empresa em relação às questões ambientais para seus amigos ou familiares, seguido de $43 \%$ que afirmaram que sempre isto acontece, conforme ilustra a figura 5. Também apontaram que, de acordo com a figura 6 , quase sempre (37\%) retransmitem estas informações para seus colegas de trabalho, seguido de $47 \%$ que evidenciaram que sempre restransmitim estas informações para seus colegas de trabalho. Fatos estes que já haviam sido destacados por Vilela Júnior e Demajorovic (2006), que no processo de educação ambiental os funcionários adquirem condições de assumir o papel de agentes de mudança em qualquer contexto e situação. Neste sentido, a empresa deve promover a curiosidade e a construção de conhecimento estimulando os empregados a contribuírem, por meio de sugestões, com o melhor desempenho pessoal e da corporação.

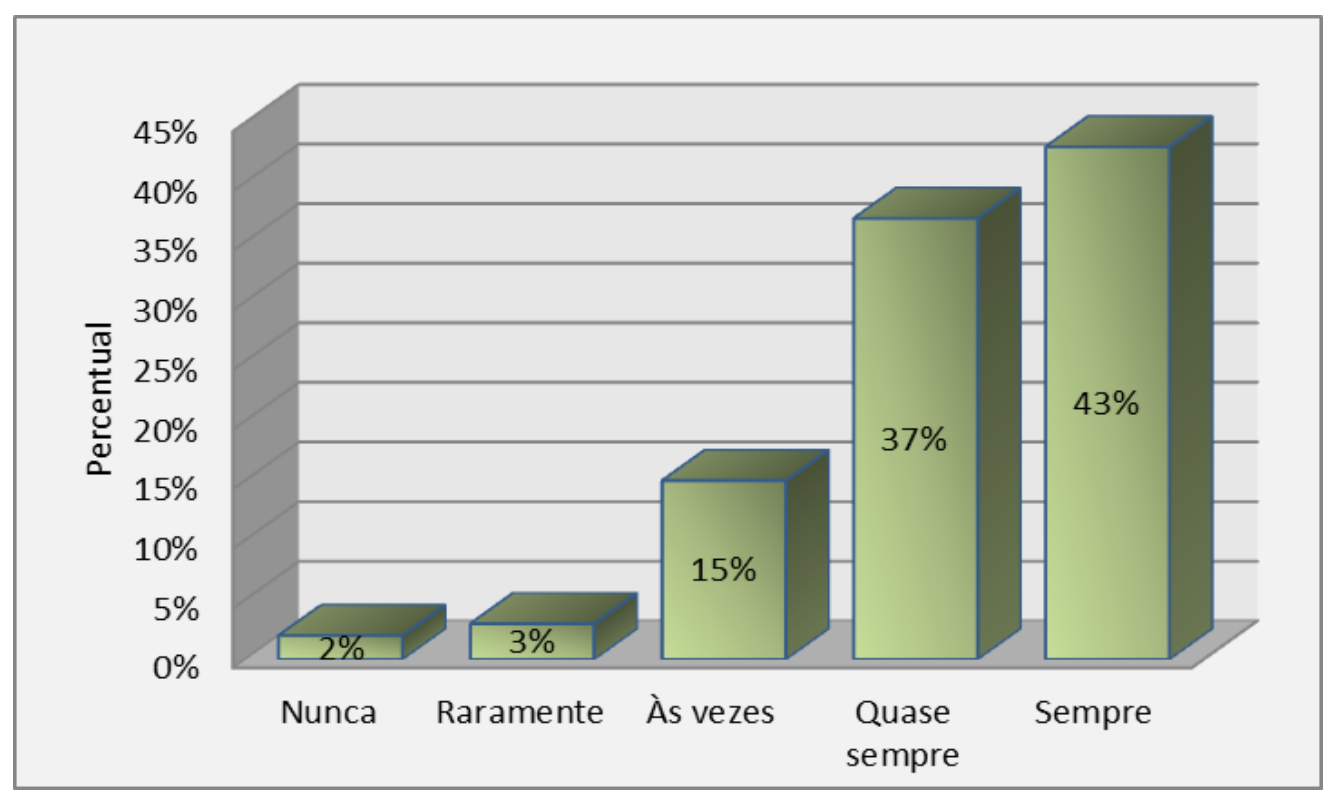

Figura 5: Frequência das informações retransmitidas para amigos ou familiares

Fonte: Elaborada pelas autoras 


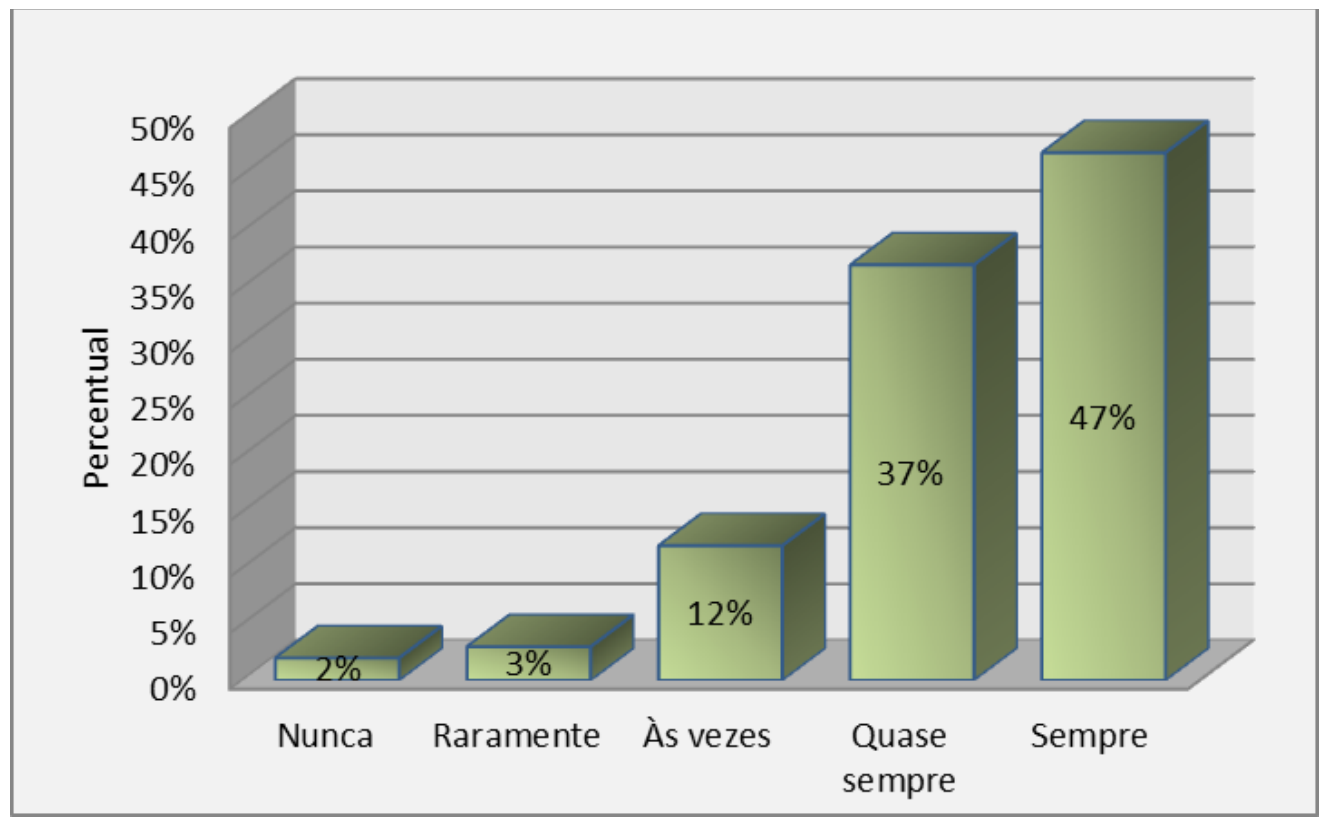

Figura 6: Frenquências das informações retransmitidas para colegas de trabalho Fonte: Elaborada pelas autoras

A penúltima questão buscou identificar qual o grau de interesse dos respondentes em relação às questões ambientais. A distribuição percentual apresentada pelos respondentes, como se vê na figura 7 , revela que $58 \%$ dos respondentes, seguido de $35 \%$, afirmam possuírem um elevado grau de interesse em relação às questões ambientais. Já 5\% afirmam ter um interesse mediano e apenas $2 \%$ apontaram pouco interesse. Estes resultados reafirmam as considerações de Penatti e Silva (2008), onde para eles a educação ambiental conduz os funcionários a uma mudança de comportamento e atitudes em relação ao meio ambiente interno e externo da sua empresa, despertando o interesse em cada colaborador na ação e busca de soluções concretas para os problemas ambientais que ocorrem principalmente no seu dia a dia.

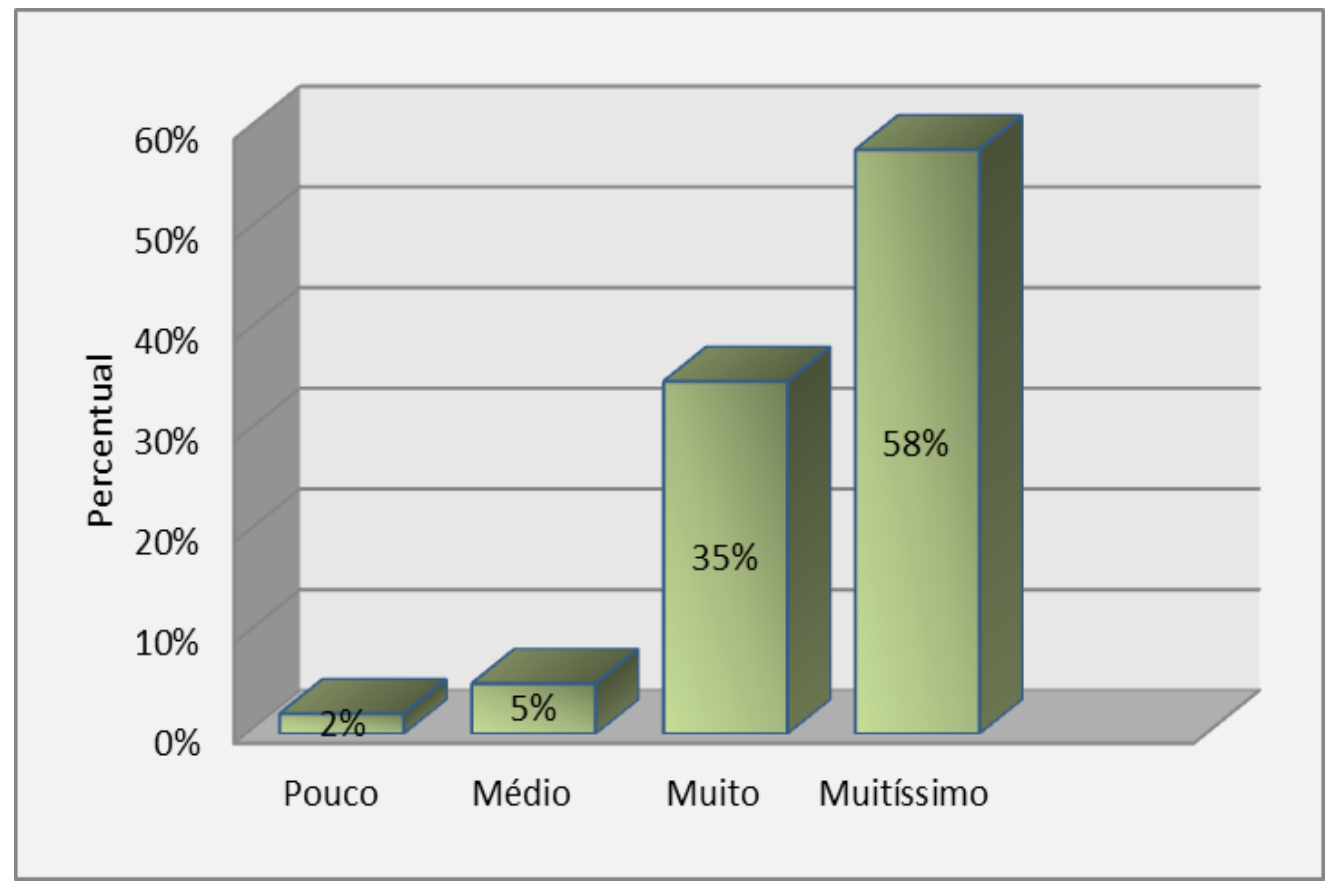

Figura 7: Grau de interesse em relação às questões ambientais

Fonte: Elaborada pelas autoras 
Já a ultima questão, objetivou colher dos respondentes o grau de eficácia das ações praticadas por sua empresa que visam a educação ambiental do seu público externo (clientes, fornecedores, acionistas e comunidade local). Os dados revelaram que, conforme a figura 8 , somente $2 \%$ indicaram que sua empresa possui pouca eficácia em relação a promover a educação ambiental com seu público externo, $38 \%$ disseram que sua empresa é muito eficaz na promoção dessas práticas, seguido de $50 \%$ que disseram que sua empresa possui um elevado grau de eficácia quando promove a educação ambiental com seu público externo. Fatos estes que como bem apontou Rocha (2000) apud Silva (2005), e que se confirmam, o conceito de educação ambiental refere-se a um processo de tomada de consciência política, institucional e comunitária da realidade ambiental, do homem e da sociedade, para analisar, em conjunto com seu público externo, por meio de mecanismos formais e não formais, as melhores alternativas de proteção da natureza e do desenvolvimento socioeconômico do homem e da sociedade.

Observa-se também que os dados confirmam as considerações de Vilela Júnior e Demajorovic (2006) onde enfatizam que as empresas devam praticar ações de educação ambiental tanto no seu ambiente interno quanto no seu ambiente externo, pois estão lidando com pessoas, com individualidades, com histórias de vida, com crenças, valores e culturas, ou seja, com hábitos que determinam comportamentos, consolidando-se, então, um cenário muito mais complexo.

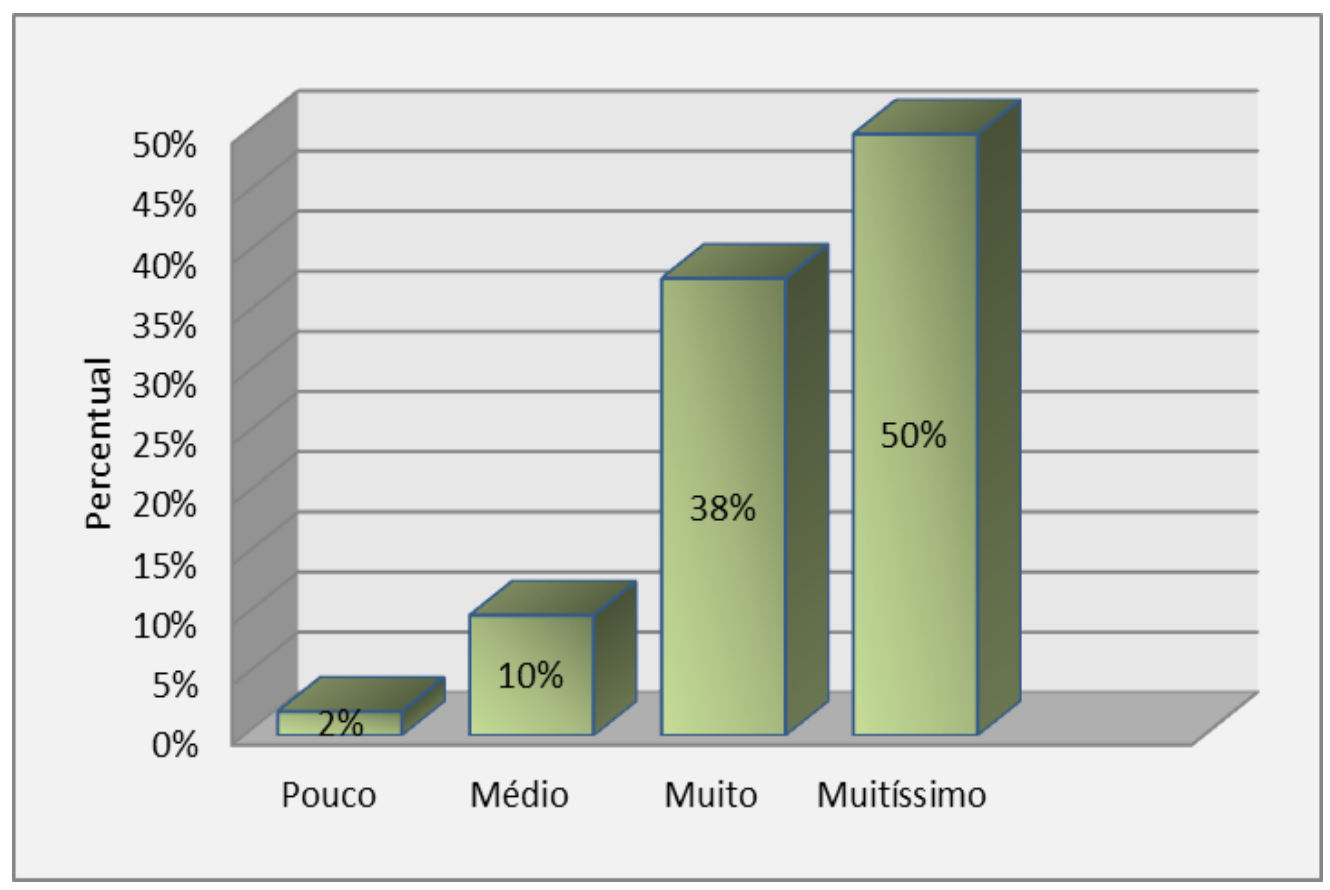

Figura 8: Grau de eficácia das ações praticadas pela empresa

Fonte: Elaborada pelas autoras

\section{CONCLUSÃO}

Considerando ter sido o objetivo geral deste trabalho o de verificar, a partir da percepção de colaboradores, se a empresa pesquisada, localizada no Polo Industrial de Manaus - PIM e que possui Sistema de Gestão Ambiental - SGA, contribui para a educação ambiental dos seus funcionários ou em suas práticas pessoais e profissionais, bem como considerando os resultados aqui encontrados e discutidos, é possível concluir que a EA, como uma ferramenta advinda do SGA, contribui para o processo de conscientização dos colaboradores, onde estes adquirem condições de assumir o papel de agentes de mudança em qualquer contexto e situação, influenciando, inclusive, em suas praticas pessoais e profissionais, bem como, adquirem a capacidade de disseminar informações sobre a temática ambiental para aqueles que o circundam, como seus familiares, amigos e colegas de trabalho; além de possuírem um elevado grau de interesse em relação às questões ambientais, também percebem tais práticas com extremo valor para enfrentar delicados problemas ambientais. Percepções estas que confirmam aspectos contemplados pela literatura sobre o tema. 
Assim, observa-se que os objetivos do trabalho foram cumpridos e pode-se constatar que a educação ambiental nas empresas tem um papel muito importante, pois conduz os profissionais a uma mudança de comportamento e atitudes em relação ao meio ambiente interno e externo às organizações, despertando a conscientização para a ação e a busca de soluções concretas para os problemas ambientais que ocorrem principalmente no seu dia a dia, no seu local de trabalho e na execução de suas tarefas.

\section{REFERÊNCIAS}

ALCANTARA, Larissa; SILVA, Maria Clara. Educação Ambiental e os Sistemas de Gestão Ambiental no Desafio do Desenvolvimento Sustentável. v(5), n5, p. 734 - 740, 2012. Revista Eletrônica em Gestão, Educação e Tecnologia AmbientalREGET/UFSM (e-ISSN: 2236-1170). Disponível em <http://cascavel.ufsm.br/ revistas/ojs-2.2.2/index.php/reget/article/download/4198/2802>. Acesso em: 28 de Março de 2014.

ASSOCIAÇÃO BRASILEIRA DE NORMAS TÉCNICAS. ABNT NBR ISO 14.001. Sistemas da gestão ambiental - Requisitos com orientações para uso. Rio de Janeiro, 2004.

PRESTES, Maria Lucia de Mesquita. A pesquisa e a construção do conhecimento científico: do planejamento aos textos, da escola à academia. $3^{\text {a }}$ ed. São Paulo, Rêspel, 2007.

MACEDO, Luiz Manuel. Programas Ambientais e suas Resoluções no Tratamento de Resídios Sólidos pelas Indústrias Petrolíferas no Brasil. Universidade Candido Mendes, Pós-Graduação "Lato Sensu", Instituto a Vez do Mestre. Rio de Janeiro, 2010. Disponível em<http://www.avm.edu.br/docpdf/monografias_publicadas/T205936.pdf>. Acesso em: 28 de Março de 2014.

MEDEIROS, Tiziana Azario de. Educação Ambiental e o processo produtivo: um estudo de caso nas empresas do Polo Industrial de Manaus/AM. Manaus: UFAM/Fundação Universitária Iberoamericana, 2004.

MOLIN, Michele. Diagnóstico Ambiental para a Implementação de um Sistema de Gestão Ambiental. Estudo de Caso: Gabriella Revestimentos Cerâmicos LTDA. Universidade do Extremo Sul CatarinenseUNESC. Junho, 2009. Disponível em <http://www.bib.unesc.net/biblioteca/sumario/00003D/00003DCA. pdf $>$. Acesso em: 03 de Abril de 2014.

MOTTA, Márcio Jardim. A educação ambiental nas empresas e o Sistema de Gestão Ambiental, 2010. Disponível em: http://www.ietec.com.br/site/techoje/categoria/detalhe_artigo/135. Acesso em: 07 de abril de 2014.

PENATTI, Fabio Eduardo; SILVA, Paulo Marcos. Coleta Seletiva como Processo de Implantação de Programas de Educação Ambiental em Empresas: Caso da Bioagri Laboratorios. In: $1^{\circ}$ Simpósio de Pós-Graduação em Geografia do Estado de São Paulo, 2008, Rio Claro. Anais... Rio Claro: UNESP, 2008. Disponível em: http://www.rc.unesp.br/igce/simpgeo/765-781fabio.pdf. Acesso em: 08 de maio de 2014.

RODRIGUES, Jaqueline; KOPP, Nathalie; LIMA, Isaura; REIS, Dálcio; OLIVEIRA, Ivanir. Implantação do Sistema de Gestão Ambiental Segundo a NBR ISO 14001:uma pesquisa de campo em empresa do ramo metalúrgico. Quarto encontro de engenharia e tecnologia dos Campos Gerais. Agosto, 2008. Disponível em <http://www.4eetcg.uepg.br/oral/28_1.pdf>. Acesso em : 01 de Abril de 2014.

SILVA, Enedina; SILVA, Claudete; SILVA, Fabiana. A educação ambiental na empresa como suporte para a implementação de sistema de gestão ambiental. XXV Encontro Nac. de Eng. de Produção - Porto Alegre, RS, Brasil, 29 out a 01 de nov de 2005. Disponívelem <http://www.abepro.org.br/biblioteca/enegep2005_enegep1002_1117.pdf>. Acesso em: 27 de Fevereiro de 2014.

TORRES, Maria; BALASSIANO, Laila. Educação ambiental e princípio de sustentabilidade no mundo moderno. Revista Práxisano ii, no 4 - agosto 2010. Disponível em <http://web.unifoa.edu.br/praxis/numeros/04/29.pdf>. Acesso em: 27 de Fevereiro de 2014. 
VALLE, Cyro Eyer do. Qualidade Ambiental - ISO 14.000. 5a ed. São Paulo: Senac, 2006.

VILELA JÚNIOR, Alcir; DEMAJOROVIC, Jacques. Modelos e ferramentas de gestão ambiental: desafios e perspectivas para as organizações. São Paulo: Senac, 2006. 